Fukushima J. Med. Sci.,

Vol. 60, No. 1, 2014

[Original Article]

\title{
PSYCHOLOGICAL DISTRESS AFTER THE GREAT EAST JAPAN EARTHQUAKE AND FUKUSHIMA DAIICHI NUCLEAR POWER PLANT ACCIDENT : RESULTS OF A MENTAL HEALTH AND LIFESTYLE SURVEY THROUGH THE FUKUSHIMA HEALTH MANAGEMENT SURVEY IN FY2011 AND FY2012
}

\author{
HIROOKI YABE ${ }^{1,2)}$, YURIKO SUZUKI ${ }^{3,4)}$, HIROBUMI MASHIKO ${ }^{1,2)}$, YOKO NAKAYAMA ${ }^{1,5)}$, \\ MITSURU HISATA $^{1,6)}$, SHIN-ICHI NIWA ${ }^{1,7)}$, SEIJI YASUMURA ${ }^{1,4)}$, SHUNICHI YAMASHITA ${ }^{1,8)}$, \\ KENJI KAMIYA ${ }^{1,9}$, MASAFUMI ABE ${ }^{1)}$, ON BEHALF OF THE MENTAL HEALTH GROUP \\ OF THE FUKUSHIMA HEALTH MANAGEMENT SURVEY
}

\begin{abstract}
${ }^{1)}$ Radiation Medical Science Center for the Fukushima Health Management Survey and ${ }^{2)}$ Department of Neuropsychiatry, School of Medicine, Fukushima Medical University, Fukushima, Japan, ${ }^{3)}$ Department of Adult Mental Health, National Institute of Mental Health, National Center of Neurology and Psychiatry Japan, ${ }^{4}$ Department of Public Health, School of Medicine, Fukushima Medical University, Fukushima, Japan, ${ }^{5}$ Faculty of Nursing, University of Kochi, Kochi, Japan, ${ }^{6}$ Faculty of Human Sciences, Sophia University, Tokyo, Japan, ${ }^{7}$ Department of Psychiatry, Aizu Medical Center, Fukushima Medical University, Fukushima, Japan, ${ }^{8)}$ Atomic Bomb Disease Institute, Nagasaki University, Japan, ${ }^{9}$ Research Institute for Radiation Biology and Medicine, Hiroshima University, Hiroshima, Japan
\end{abstract}

(Received January 21, 2014 accepted April 1, 2014)

\begin{abstract}
Background] On 11 March 2011, the Great East Japan Earthquake followed by a gigantic tsunami hit the Pacific coast of Northeast Japan (Tohoku) and damaged Tokyo Electric Power Company's Fukushima Daiichi Nuclear Power Plant, causing a radiation hazard in the entire Fukushima Prefecture. The radiation dose exposed either externally and internally in Fukushima residents have been evaluated to be low so far and it is hardly believed that they may have any direct radiation risk on physical condition. The purpose of this report is, therefore, to describe results of a mental health and lifestyle survey intended to facilitate adequate care for residents who are at a higher risk of developing mental health problems after the complicated accident. [Participants and Methods] The target population of this survey is the residents of evacuation zones including Hirono Town, Naraha Town, Tomioka Town, Kawauchi Village, Okuma Town, Futaba Town, Namie Town, Katsurao Village, Minamisoma City, Tamura City, Yamakiya district of Kawamata Town, and Iitate Village. The targeted population was 210,189 in fiscal year 2011 (FY2011) and 211,615 in fiscal year 2012 (FY2012). Questionnaires have been mailed since January 2012, and subsequently, January 2013, 10 and 22 months after the disaster. Among of them, children $63.4 \%$, adults $40.7 \%$ for FY2011, and children $41.0 \%$, adults $29.7 \%$ for FY2012 responded to the questionnaires mailed. [Results] Sociodemographic data showed that many evacuee households were separated after the disaster and had to move several times. K6 was used in this survey to estimate general mental health. The proportion (14.6\% in FY2011 and 11.9\% inFY2012) of adults who scored above the K6 cut-off $(\geq 13)$ for general mental health was higher than usual, indicating severe mental health problems among evacuees. The proportion (21.6\% in FY2011 and 18.3\% inFY2012) of adults who scored above the cut-off ( $\geq 44$ ) of PTSD checklist (PCL), reflecting traumatic symptoms, was almost equal to that of the workers after the 9.11 World Trade Center attacks. These results also indicate the presence of severe traumatic problems among evacuees. The proportions of children (4-6
\end{abstract}

Corresponding author: Hirooki Yabe MD, PhD E-mail : hyabe@fmu.ac.jp

https://www.jstage.jst.go.jp/browse/fms http://www.fmu.ac.jp/home/lib/F-igaku/ 
years old) and children of primary school age (6-12 years old) who scored above the cut-off $(\geq 16)$ of Strengths and Difficulties Questionnaire (SDQ) reflecting the mental health status in children, $24.4 \%$ and $22.0 \%$ in the survey of FY2011, were double the usual state respectively, whereas $16.6 \%$ in children of 4-6 years old and $15.8 \%$ in children of 6-12 years old in FY2012 were 1.5 times. These findings also disclosed the presence of severe mental difficulties in children, with relative improvement year by year. [Conclusion] As revealed by the present mental health survey, the earthquake and tsunami followed by the nuclear accident caused psychological distress among residents in Fukushima prefecture. Continuous survey and mental care programs are required.

Key words : Earthquake, Tsunami, Nuclear Accident, Mental Health, Survey

\section{INTRODUCTION}

The Great East Japan Earthquake hit mainly the Pacific coast of three prefectures (Miyagi, Iwate and Fukushima) in Northeast (Tohoku area) Japan at 14 : 46 on 11 March 2011. The earthquake was followed by a gigantic tsunami which, to make matters worse, damaged the Tokyo Electric Power Company's (TEPCO) Fukushima Daiichi Nuclear Power Plant (NPP), causing a radiation hazard in Fukushima Prefecture. Although the exposure dose externally and internally just after the accident itself is estimated to be very low and it is very difficult to confirm the direct effect of radiation exposure on any physical condition for the residents in Fukushi$\mathrm{ma}^{1)}$, the TEPCO-Fukushima Daiichi NPP accident has cast a wide-ranged shadow on the mental health of inhabitants who fear radioactive contamination. Unfortunately it was very difficult for the Japanese mental health community to immediately respond to this crisis in comparison with the past experience with purely natural disasters in Japan. This is exactly unexpected and unprecedented worst nuclear accident.

According to a review of the existing literature on mental health after the previous nuclear power plant accidents, psychological reactions observed in the Three Mile Island and Chernobyl accidents also occurred in Fukushima ${ }^{2,3)}$. That is, the affected people experienced confusion, distrust, mental health problems, and stigma. Twenty years after the Chernobyl accident, WHO concluded that mental health is the most serious public health problem ${ }^{4,5}$ as a result of that nuclear accident and the same problems might be observed in Fukushima as well.

These mental health problems can be devastating. Based on clinical observation, the primary problem seems to be anxiety regarding the effects of radiation on health (especially for children), community, lifestyle, and the economy. Although these are rational concerns that we should not dismiss, a post-
Chernobyl study showed that diagnoses of mental disorders increased in the aftermath of the incident, which suggests that the observed anxiety issues may represent legitimate disorders when they persist. Another issue observed in Fukushima and learnt from previous nuclear power plant accidents is the loss of control that the affected people experienced over their lives and their powerlessness as victims. Rather than simply offer services or health check-ups, a better solution would support them in making their own decisions based on sound information.

Fukushima prefecture started the Fukushima Health Management Survey to monitor its residents' long-term health, to promote their future wellbeing, and to determine whether long-term low-dose radiation exposure affects health. This multifaceted survey includes a basic survey for the general population and a more targeted detailed survey. Mental health is a focal point of the detailed survey, and a mail-based, self-administrated survey was conducted in January 2012, and subsequently, January 2013, 10 and 22 months after the disaster. The present report briefly describes the results of the survey and compares the results in two time points ${ }^{6-8)}$.

\section{Participants}

The target population consists of officially registered residents of any age from the nationally designated evacuation zones including Hirono Town, Naraha Town, Tomioka Town, Kawauchi Village, Okuma Town, Futaba Town, Namie Town, Katsurao Village, Minamisoma City, Tamura City, Yamakiya district of Kawamata Town, and Iitate Village. The target population was 210,189 in fiscal year 2011 (FY2011), and 211,615 in fiscal year 2012 (FY2012). The survey response rates were : children $63.4 \%$, adults $40.7 \%$ for FY2011, and children $41.0 \%$, adults $29.7 \%$ for FY2012. 


\section{Methods}

The primary purposes of the Fukushima Health Management Survey are to monitor the long-term health and daily lives of residents of Fukushima and to provide them proper care. The entire protocol of this survey is published elsewhere ${ }^{9)}$. We send the self-administrated mental health questionnaire to the target population.

Socioeconomic and disaster-related variables were asked, including age, gender, current living situations such as change in work, income, number of times moving, number of cohabitants, and experience related to the earthquake, tsunami, and NPP accident, specifically, witnessing or hearing any hydrogen explosion at the NPPs.

To assess mental health status of residents over 15 years old, Kessler's K6 ${ }^{10)}$, PTSD Checklist Stressor-Specific Version (PCL-S) ${ }^{11)}$ were used. Additionally, CAGE was used to assess problem drinking in the survey in FY2012.

We measured non-specific mental health distress as a primary outcome by $\mathrm{K} 6$. In the K6, participants were asked if they had the following symptoms during the past 30 days : feeling so sad that nothing could cheer you up, feeling nervous, hopeless, restless or fidgety, feeling everything was an effort, and feeling worthless. Each question was rated on a 5-point Likert scale from zero (none of the time) to four (all of the time), with higher scores signifying worse mental health status (range : $0-24)$. The Japanese version of the K6 has been validated $^{12,13)}$.

PCL-S was used to measure traumatic symptoms, and we specified the event as the experience of the Great East Japan Earthquake and the disaster. We summed up the responses to the 17 Likert-like items in the PCL and classified a responder as having probable PTSD if the total score was $\geq 44^{11)}$, where each item was scored as 1-5 (corresponding respectively to not at all, a little bit, moderately, quite a bit, or extremely).

In the survey of FY2012, other measures were added, which include the CAGE questionnaire for alcohol abuse ${ }^{14)}$, the Sheehan Disability Scale to estimate the extent to which emotional problems disrupted work, social life, and family and home responsibilities ${ }^{15,16)}$, and Lubben's Social network ${ }^{17,18}$.

Regarding the risk perception of radiation health effect, three items on perceptions of immediate, delayed, and genetic effects were asked ${ }^{19)}$. The items were translated forward and subsequently backward and modified after the discussion with the authors, with the 4-point Likert scale ranging from very unlikely, to very likely.

To assess children's mental health status, Strength and Difficulties Questionnaire (SDQ) was used $^{20,21)}$, which consists of 25 questions to the parents concerning both positive and negative behavior of their child. There is one subscale for prosocial behavior (social strength; up to 10 points) and four subscales for difficult behaviors (emotional symptoms, conduct problems, hyperactivity/inattention, and peer relationship problems ; up to 40 points in total). For SDQ-prosocial behavior, higher scores indicate more positive behavior, and for SDQ-difficult behavior, higher scores indicate more problematic behavior.

This survey was approved by the ethics review committee of Fukushima Medical University (No. 1316).

\section{RESULTS}

Demographic and current living situation data are presented in Table 1 . With regard to current living situation in FY2012, 14,923 people (39.2\%) answered that they live separately from any family member who used to live with them before the disaster. The number of cohabitants before the disaster varied from 0 (meaning living alone) among 57 people $(0.2 \%)$, one among 2,341 people $(6.6 \%)$, two among 7,882 people $(22.1 \%)$, to more than three among 25,401 people $(71.1 \%)$. At the survey, the current number of cohabitants were from 0 (meaning living alone), 85 people $(0.2 \%)$; one, 5,130 people (13.8\%) ; two, 12,956 people (34.9\%) ; and more than three, 18,925 people (51.1\%). Regarding the number of times moving, 3,619 people $(10.1 \%)$ reported zero, 3,998 people (11.2\%) once, 4,656 people $(13.0 \%)$ twice, 6,366 people $(17.8 \%)$ three times, 6,085 people (17.0\%) four times, and 11,090 people (30.9\%) moved more than 5 times (Table1).

\section{General mental health}

Among the valid responses $(n=59,807$ in FY2011, $n=32,508$ in FY2012), the overall mean score of $\mathrm{K} 6$ was 6.3 (5.5 in males and 6.8 in females) in FY2011, and 5.7 (5.1 in males and 6.3 in females) in FY2012. Those who scored 13 and above on K6 were 8,717 (14.6\%) in total, 3,133 (11.9\%) among males and 5,584 (16.7\%) among females in FY2011, versus 3,865 (11.9\%), 1,468 (10.0\%) and 2,397 (13.5\%), respectively in FY2012. The distribution of K6 in FY2011 and FY2012 is presented in Figure 
Table 1. Participants' sociodemographic information and living situations in survey FY2011 and FY2012 (Adults)

\begin{tabular}{|c|c|c|c|c|}
\hline & \multicolumn{2}{|c|}{ FY2011 } & \multicolumn{2}{|c|}{ FY2012 } \\
\hline & $n$ & $\% /$ mean & $n$ & $\% /$ mean \\
\hline Age (mean) & & 55.5 & & 59.0 \\
\hline Gender & 73,433 & & 39,495 & \\
\hline Males & 32,301 & 44.0 & 17,624 & 44.6 \\
\hline Females & 41,132 & 56.0 & 21,871 & 55.4 \\
\hline \multicolumn{5}{|l|}{ Living place } \\
\hline In Fukushima prefecture & 59,435 & 80.9 & 31,965 & 80.9 \\
\hline Out of Fukushima prefecture & 13,998 & 19.1 & 7,530 & 19.1 \\
\hline \multicolumn{5}{|c|}{ Experience of disaster (multiple answer) } \\
\hline Earthquake & 69,700 & & 35,346 & \\
\hline Tsunami & 14,757 & & 7,563 & \\
\hline Nuclear Power Plant Accident & 38,392 & & 34,954 & \\
\hline None & 1,095 & & 307 & \\
\hline \multicolumn{5}{|l|}{ Living arrangement } \\
\hline Evacuation Shelter & $734 * 1$ & 1.3 & $15,727^{* 2}$ & \\
\hline Temporary housing & $6,896^{* 1}$ & 12.0 & $7,295^{* 2}$ & \\
\hline Rental house, apartment & $22,947 * 1$ & 40.0 & $19,059 * 2$ & \\
\hline Relative's home & $2,460 * 1$ & 4.3 & $16,156^{* 2}$ & \\
\hline Own home & $21,459^{* 1}$ & 37.5 & $10,442^{* 2}$ & \\
\hline Other & $2,778^{* 1}$ & 4.9 & $3,442 * 2$ & \\
\hline $\begin{array}{l}\text { Living separately from } \\
\text { any family member }\end{array}$ & & & 14,923 & 39.2 \\
\hline \multicolumn{5}{|l|}{ Number of cohabitants } \\
\hline \multicolumn{5}{|l|}{ Before the disaster } \\
\hline 0 (Living alone) & & & 57 & 0.2 \\
\hline 1 & & & 2,341 & 6.6 \\
\hline 2 & & & 7,882 & 22.1 \\
\hline $3+$ & & & 25,401 & 71.1 \\
\hline \multicolumn{5}{|l|}{ Current } \\
\hline 0 (Living alone) & & & 85 & 0.2 \\
\hline 1 & & & 5,130 & 13.8 \\
\hline 2 & & & 12,956 & 34.9 \\
\hline $3+$ & & & 18,925 & 51.1 \\
\hline \multicolumn{5}{|l|}{ Number of times moving } \\
\hline 0 & & & 3,619 & 10.1 \\
\hline 1 & & & 3,998 & 11.2 \\
\hline 2 & & & 4,656 & 13.0 \\
\hline 3 & & & 6,366 & 17.8 \\
\hline 4 & & & 6,085 & 17.0 \\
\hline $5+$ & & & 11,090 & 30.9 \\
\hline Change of work & 36,507 & 54.0 & 16,652 & 50.7 \\
\hline \multicolumn{5}{|l|}{ Current living circumstances } \\
\hline Poor off & & & 6,110 & 17.1 \\
\hline Relatively poor off & & & 10,990 & 30.7 \\
\hline Normal & & & 17,443 & 48.7 \\
\hline Relativel well off & & & 929 & 2.6 \\
\hline Well off & & & 332 & 0.9 \\
\hline
\end{tabular}

*1 Number of people living there at the time of survey

*2 Number of people having lived there 


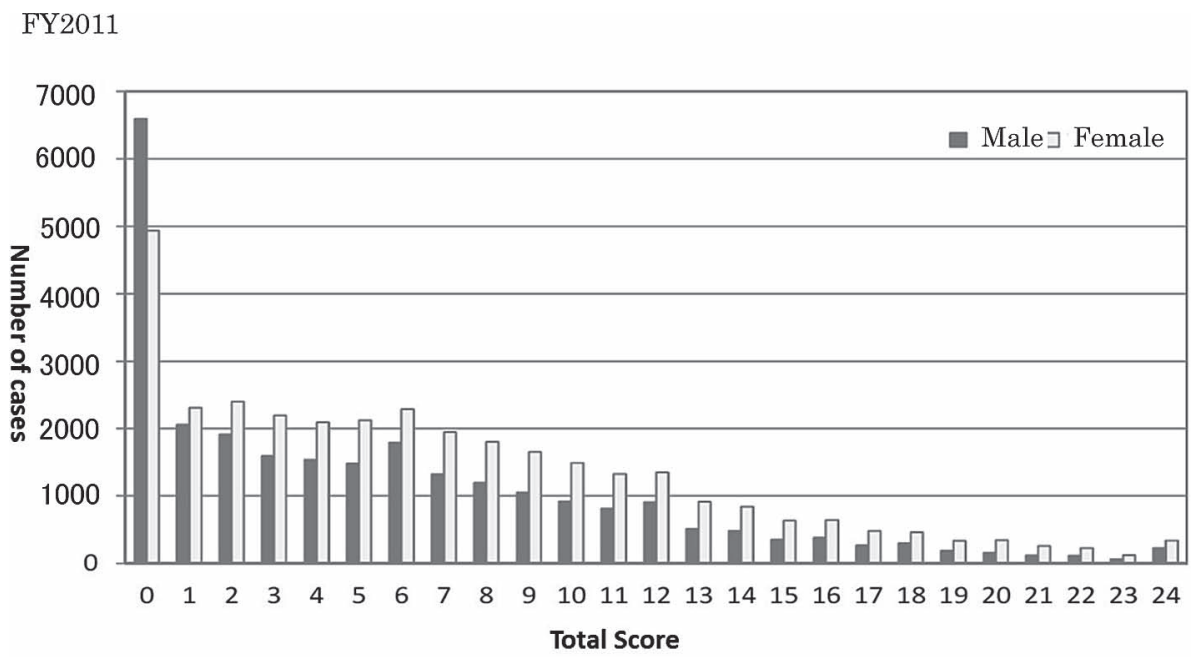

FY2012

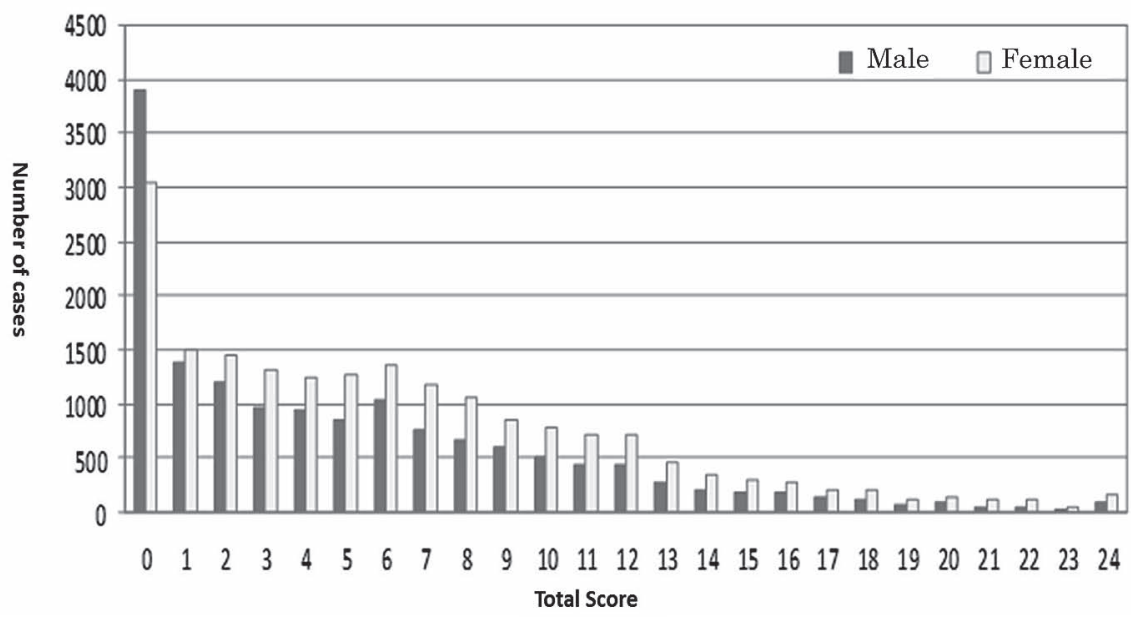

Fig. 1. Distribution of score of non-specific mental health problems measured by K6 in survey of FY2011 and FY2012.

1. Regarding social disability due to mental health problems, the number of those who responded as "none of the time" was 19,173 (56.8\%), "a little of the time" was 8,351 (24.8\%), "some of the time" was $4,015(11.9 \%)$, "most of the time" was 985 $(2.9 \%)$, and "all of the time" was $1,213(3.6 \%)$ in FY2012.

\section{Traumatic symptom}

Among the valid responses $(n=60,704$ in FY2011, $n=32,246$ in FY2012), the overall mean score of PCL-S was 33.0 (31.2 in males and 34.4 in female) in FY2011, and 31.7 (30.6 in males and 32.6 in females) in FY2012. Those who scored 44 and above on PCL were 13,111 (21.6\%) in total, 4,864 (18.2\%) among males and 8,247 (24.3\%) among females in FY2011, versus 5,892 (18.3\%), 2,420 (16.6\%) and 3,472 (19.6\%), respectively in FY2012.
The distribution of PCL-S in FY2011 and FY2012 is presented in Figure 2. Regarding social disability due to traumatic symptoms, those who responded yes were $8,127(25.0 \%)$ and those who responded no were $24,443(75.0 \%)$.

\section{Alcohol problem (CAGE)}

Among those who drink alcohol, 5,690 (21.1\%) felt the need to cut down on drinking, 1,819 (6.8\%) reported to be annoyed by criticism of their drinking behavior, 2,522 (9.4\%) felt guilty about drinking, and $1,642(6.1 \%)$ felt the need of drink as eye-opener. (Table 2)

\section{Risk perception of radiation}

Regarding the degree of risk perception of radiation health effects in FY2012 survey, 3,045 (9.3\%) respondents reported an immediate effect is very 
FY2011

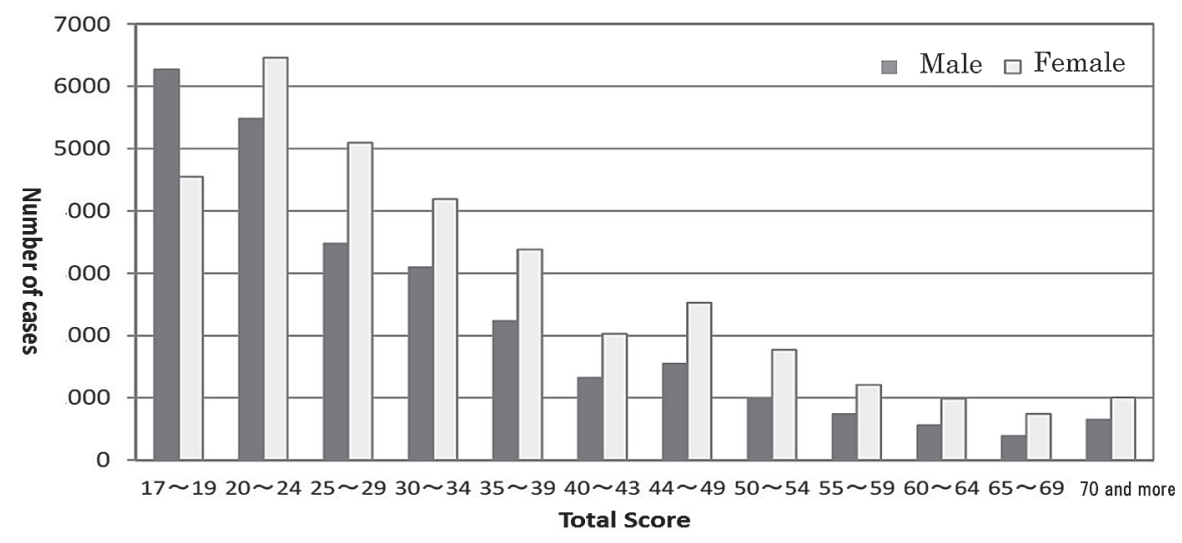

FY2012

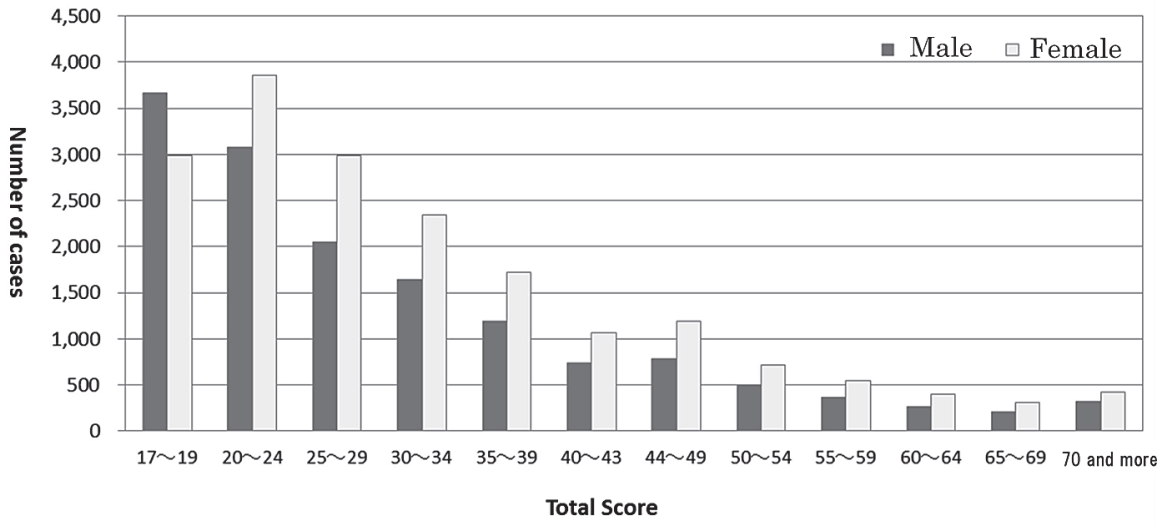

Fig. 2. Distribution of score of traumatric symptoms measured by PTSD checklist (PCL), specific version in survey of FY2011 and FY2012

likely, 6,352 (19.5\%) reported delayed effects, and $8,215(25.4 \%)$ reported genetic effects due to exposure of the radioactive materials from the Fukushima Nuclear Power Plant. Details are presented in Table 3 .

\section{Children's mental health status}

Demographics of children who returned the surveys are presented in Table 4 . The prevalence difficulties above the cut-off $(>=16)$ on SDQ in the survey of FY2011 was $24.4 \%$ in children of 4-6 yearold, $22.0 \%$ in children of primary school age (6-12 years old), and $16.2 \%$ in children of junior high school age (12-15 years old). Those in the survey of FY2012 were $16.6 \%$ in children of 4-6 year-old, $15.8 \%$ in children of primary school age, and $12.8 \%$ in children of junior high school age. The comparison of the mean total difficulties scores and proportion of above-cut-off results in FY2011 and FY2012 by different age groups are presented in Table 5 .

\section{DISCUSSION}

The mental health and lifestyle survey was conducted twice (10 and 22 months after the disaster) to provide adequate mental care and lifestyle support for evacuees who are at a higher risk of developing mental health and lifestyle problems. It was one of four detailed surveys in a large-scale cohort study of the Fukushima Health Management Survey $^{9}$.

As shown in the sociodemographic information of evacuees, many people (39.2\%) were compelled to live separately from their usual household members after the disaster and had to move several times. Two or more moves and suddenly living alone likely provoke substantial mental burdens as evidenced by previous report from Chernobyl ${ }^{1,2)}$.

K6 was employed in this survey to estimate general mental health of evacuees. The percentage of adults who scored above the cut-off points of 13 
Table 2. Results of mental health assessments in survey FY2011 and FY2012 (Adults)

\begin{tabular}{|c|c|c|c|c|}
\hline & \multicolumn{2}{|c|}{ FY2011 } & \multicolumn{2}{|c|}{ FY2012 } \\
\hline & $n$ & $\% /$ mean & $n$ & $\% /$ mean \\
\hline \multicolumn{5}{|l|}{ Non-specific mental health (K6) } \\
\hline Mean $(n=59,807$ in FY2011, $n=32,508$ in FY2012) & & 6.3 & & 5.7 \\
\hline Males $(n=26,321$ in FY2011, $n=14,710$ in FY2012) & & 5.5 & & 5.1 \\
\hline Females ( $n=33,486$ in FY2011, $n=17,797$ in FY2012) & & 6.8 & & 6.3 \\
\hline$>=13$ & 8,717 & 14.6 & 3,865 & 11.9 \\
\hline Males & 3,133 & 11.9 & 1,468 & 10.0 \\
\hline Females & 5,584 & 16.7 & 2,397 & 13.5 \\
\hline \multicolumn{5}{|l|}{ Traumatic symptoms (PCL) } \\
\hline Mean $(n=60,704$ in FY2011, $n=32,246$ in FY2012) & & 33.0 & & 31.7 \\
\hline Males $(n=26,752$ in FY2011, $n=14,543$ in FY2012) & & 31.2 & & 30.6 \\
\hline Females ( $n=33,952$ in FY2011, $n=17,703$ in FY2012) & & 34.4 & & 32.6 \\
\hline$>=44$ & 13,111 & 21.6 & 5,892 & 18.3 \\
\hline Males & 4,864 & 18.2 & 2,420 & 16.6 \\
\hline Females & 8,247 & 24.3 & 3,472 & 19.6 \\
\hline \multicolumn{5}{|l|}{ Problem drinking (CAGE) } \\
\hline Cut down-yes $(n=26,981)$ & & & 5,690 & 21.1 \\
\hline Annoyed-yes $(n=26,744)$ & & & 1,819 & 6.8 \\
\hline Guilty-yes $(n=26,761)$ & & & 2,522 & 9.4 \\
\hline Eye-opener-yes $(n=26,862)$ & & & 1,642 & 6.1 \\
\hline \multicolumn{5}{|l|}{ Social network (LSNS-6) } \\
\hline Mean $(n=34,400)$ & & & 13.1 & \\
\hline Males $(n=15,306)$ & & & 12.9 & \\
\hline Females $(n=19,093)$ & & & 13.3 & \\
\hline$<12$ & & & 13,618 & 39.6 \\
\hline Males & & & 6,308 & 41.2 \\
\hline Females & & & 7,310 & 38.3 \\
\hline
\end{tabular}

Abbreviations : K6 ; Kessler's 6, PCL ; PTSD Checklist, CAGE ; CAGE Alcohol Screening Test, LSNS-6 ; Lubben Social Network Scale 6.

Table 3. Results of risk perception of radiation health effects in survey FY2011 and FY2012

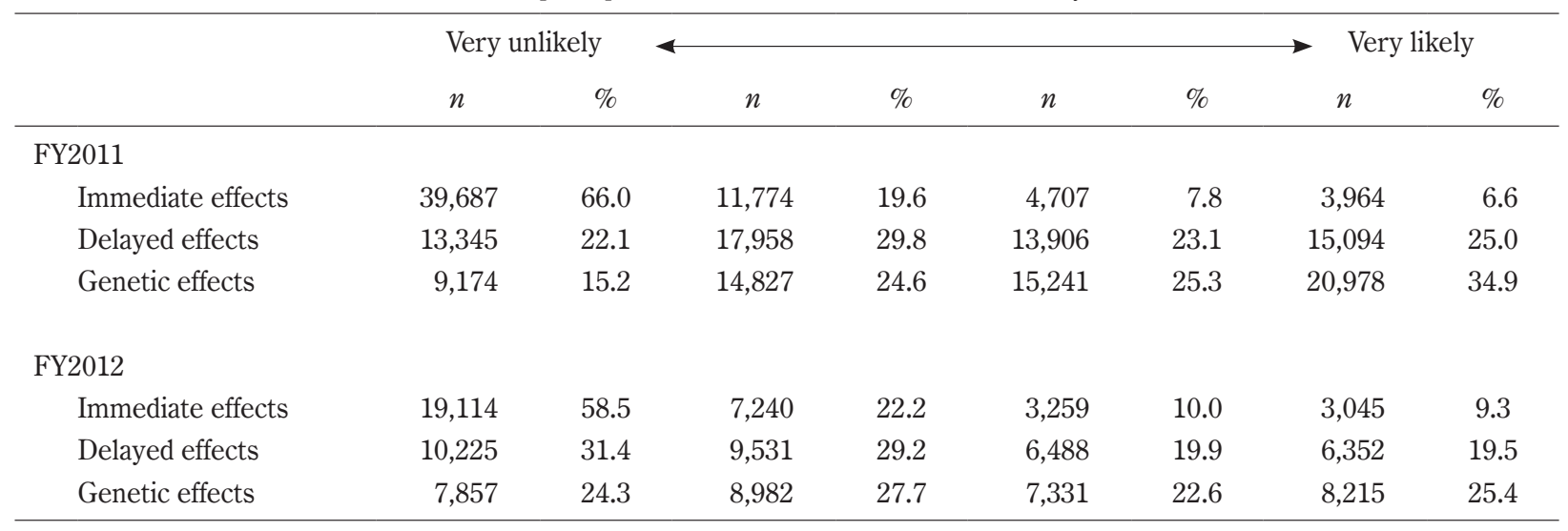


Table 4. Participants' sociodemographic information and living situations in survey FY2011 and FY2012 (Children)

\begin{tabular}{|c|c|c|c|c|}
\hline & \multicolumn{2}{|c|}{ FY2011 } & \multicolumn{2}{|c|}{ FY2012 } \\
\hline & $n$ & $\%$ & $n$ & $\%$ \\
\hline \multicolumn{5}{|l|}{ Age (mean) } \\
\hline $0-3$ years old & \multirow{2}{*}{\multicolumn{2}{|c|}{3.1}} & & 2.0 \\
\hline 4-6 years old & & & & 4.8 \\
\hline Primary school age & & 9.5 & & 9.4 \\
\hline Middle school age & & 14.0 & & 13.9 \\
\hline \multicolumn{5}{|l|}{ Gender } \\
\hline $0-3$ years old & \multirow{6}{*}{$\begin{array}{l}\text { Total : } 7,818 \\
\text { Boys : } 3,969 \\
\text { Girls : } 3,849\end{array}$} & \multirow{6}{*}{$\begin{array}{l}\text { Boys : } 50.8 \\
\text { Girls : } 49.2\end{array}$} & 1,804 & \\
\hline Boys & & & 876 & 48.6 \\
\hline Girls & & & 928 & 51.4 \\
\hline 4-6 years old & & & 1,905 & \\
\hline Boys & & & 963 & 50.6 \\
\hline Girls & & & 942 & 49.4 \\
\hline Primary school age & 7,464 & & 3,974 & \\
\hline Boys & 3,815 & 51.1 & 2,037 & 51.3 \\
\hline Girls & 3,649 & 48.9 & 1,937 & 48.7 \\
\hline Middle school age & 3,411 & & 1,796 & \\
\hline Boys & 1,717 & 50.3 & 891 & 49.6 \\
\hline Girls & 1,694 & 49.7 & 905 & 50.4 \\
\hline \multicolumn{5}{|l|}{ Living place } \\
\hline $0-3$ years old & \multirow{3}{*}{$\begin{array}{c}\text { In Fukushima } \\
\text { pref : } 5,083\end{array}$} & & 1,804 & \\
\hline In Fukushima prefecture & & \multirow{2}{*}{$\begin{array}{c}\text { In Fukushima } \\
\text { pref : } 65.0\end{array}$} & 1,194 & 66.2 \\
\hline Out of Fukushima prefecture & & & 610 & 33.8 \\
\hline 4-6 years old & \multirow{3}{*}{$\begin{array}{l}\text { Out of Fukushima } \\
\text { pref : } 2,735\end{array}$} & \multirow{3}{*}{$\begin{array}{l}\text { Out of Fukushima } \\
\text { pref : } 35.0\end{array}$} & 1,905 & \\
\hline In Fukushima prefecture & & & 1,316 & 69.1 \\
\hline Out of Fukushima prefecture & & & 589 & 30.9 \\
\hline Primary school age & 7,476 & & 3,974 & \\
\hline In Fukushima prefecture & 5,404 & 72.4 & 2,885 & 72.6 \\
\hline Out of Fukushima prefecture & 2,060 & 27.6 & 1,089 & 27.4 \\
\hline Middle school age & 3,411 & & 1,796 & \\
\hline In Fukushima prefecture & 2,734 & 80.2 & 1,436 & 80.0 \\
\hline Out of Fukushima prefecture & 677 & 19.8 & 360 & 20.0 \\
\hline
\end{tabular}

for $\mathrm{K} 6$ was $14.6 \%$ in in FY2011 and $11.9 \%$ in FY2012, respectively. Those values are substantially higher than $3 \%$ for $\mathrm{K} 6$ in the usual state as reported previously ${ }^{22)}$. The proportion above K6 cutoff $(\geq 13)$ was higher among females than males. These results suggest the severity of mental health problems in adults from the evacuation zones.

PCL was used to evaluate traumatic symptoms of evacuees. The percentage of adults who scored above the cut-off of 44 for PCL, reflecting traumatic response, was $21.6 \%$ in FY2011 and 18.3\% in FY2012, respectively. Although gender ratio, age structure and survey time after a disaster is different, those percentages are almost equal to $20.1 \%$ reported in the previous study concerning the rescue and cleanup workers after the 9.11 World Trade Center At- tacks ${ }^{23)}$. Furthermore, Our results are comparable to those og the previous research in that, L. DiGrande et al. showed that the prevalence of probable PTSD using the DSM-IV diagnostic criteria (16.1\%) was similar to the prevalence based on the PCL cutoff score 44 or $<(15.1 \%)$ among lower Manhattan residents 2-3 years after the September 11, 2001 terrorist attacks ${ }^{24)}$. The proportion above PCL cutoff ( $\geq 44$ ) was higher among females than males. These results also indicate the presence of severe traumatic problems in adults from the evacuation zones.

There is no paper published in Japan that reports the prevalence of alcohol problems using CAGE, even though the clinical utility of the CAGE is recognized. After the major natural disaster, al- 
Table 5. Results of mental health assessments in survey FY2011 and FY2012 (Children)

\begin{tabular}{|c|c|c|c|c|}
\hline & \multicolumn{2}{|c|}{ FY2011 } & \multicolumn{2}{|c|}{ FY2012 } \\
\hline & $n$ & $\% /$ mean & $n$ & $\% /$ mean \\
\hline \multicolumn{5}{|l|}{ SDQ total difficulties score } \\
\hline \multicolumn{5}{|l|}{$4-6$ years old ( $n=3,427$ in FY2011, $n=1,898$ in FY2012) } \\
\hline Mean & & 11.7 & & 10.2 \\
\hline Boys $(n=1,755$ in FY2011, $n=957$ in FY2012) & & 12.1 & & 10.8 \\
\hline Girls $(n=1,672$ in FY2011, $n=941$ in FY2012) & & 11.2 & & 9.7 \\
\hline$>=16$ & 836 & 24.4 & 316 & 16.6 \\
\hline Boys & 476 & 27.1 & 180 & 18.8 \\
\hline Girls & 360 & 21.5 & 136 & 14.5 \\
\hline \multicolumn{5}{|c|}{ Primary school age ( $n=7,450$ in FY2011, $n=3,967$ in FY2012) } \\
\hline Mean & & 11.0 & & 9.7 \\
\hline Boys ( $n=3,808$ in FY2011, $n=2,034$ in FY2012) & & 11.5 & & 10.3 \\
\hline Girls ( $n=3,642$ in FY2011, $n=1,933$ in FY2012) & & 10.4 & & 9.1 \\
\hline$>=16$ & 1,637 & 22.0 & 627 & 15.8 \\
\hline Boys & 935 & 24.6 & 372 & 18.3 \\
\hline Girls & 702 & 19.3 & 255 & 13.2 \\
\hline \multicolumn{5}{|c|}{ Middle school age ( $n=3,332$ in FY2011, $n=1,785$ in FY2012) } \\
\hline Mean & & 9.7 & & 8.8 \\
\hline Boys ( $n=1,681$ in FY2011, $n=888$ in FY2012) & & 9.5 & & 8.9 \\
\hline Girls $(n=1,651$ in FY2011, $n=897$ in FY2012) & & 9.8 & & 8.7 \\
\hline$>=16$ & 539 & 16.2 & 228 & 12.8 \\
\hline Boys & 266 & 15.8 & 119 & 13.4 \\
\hline Girls & 273 & 16.5 & 109 & 12.2 \\
\hline
\end{tabular}

Abbreviations : SDQ ; Strength and Difficulties Questionnaire.

cohol use may increase to cope with stressed life, and only limited proportion of people reportedly develop alcohol use disorder ${ }^{25)}$. However, in the context of persisting lifestyle change after a NPP accident, careful monitoring on alcohol problems is required.

SDQ was employed in this survey to assess children's mental health status. The proportion of children (4-12 years old) above 16 on SDQ (usual community setting) was $9.5 \%$. $24.4 \%$ in children of 4-6 year-old and $22.0 \%$ in children of primary school age (6-12 years old) were estimated in the survey of FY2011 were double the values of a usual state, whereas $16.6 \%$ in children of $4-6$ year-old and $15.8 \%$ in children of primary school age in the survey of FY2012 was 1.5 times than the usual ${ }^{21)}$. These results also suggest the presence of severe mental difficulties in children from the evacuation zones. However, those are relatively improved year by year.

This survey was not conducted purely for scientific research ; rather, it was conducted for needs analysis of the affected people and for provision of better services. On the basis of the survey response, the Mental Health Support Team of Fuku- shima Medical University, consisting of clinical psychologists and public health nurses, attempted to make contact via telephone with the respondents who required support, and provided them with advice and information about mental health issues. The written materials providing the telephone number of the Mental Health and Lifestyle Survey helpline for consultation were sent to the respondents who could not be reached for telephone support due to absence or other reasons. In order to provide them with telephone counseling, the written materials included a response card for them to write down any changes of general condition. The information of the respondents who definitely required continuous support was shared with municipal governments, which worked with the Fukushima Centre for Disaster Mental Health as needed.

The survey team worked closely with service providers by providing training for mental health and radiation issues to create a better liaison system in the community. The team also worked with local mental health care ('kokoro no kea' in Japanese) centres by referring follow-up cases in the community to the centres. However, more dialogue and collab- 
oration with residents is required for the researchers to effectively conduct the survey and the mental care.

As revealed by the present mental health survey, the earthquake and tsunami followed by the nuclear power plant accident caused psychological distress among residents in Fukushima prefecture. As described above, this survey is not purely for academic purpose, but for needs assessment and prioritizes those who have probable mental health problem for mental health care. Although the target population of the survey is large, at the same time, better response rate and validation of the cut-off in use of this specific disaster warrants further effort. In addition, continuous survey and proper mental health care programs are strongly required.

\section{ACKNOWLEDGMENTS}

This survey was conducted as part of Fukushima Prefecture's post-disaster recovery plans and was supported by the national "Health Fund for Children and Adults Affected by the Nuclear Incident." Conflicts of interest : None declared. We thank Professor Kenneth E. Nollet (Director, Department of International Cooperation) for helpful advice.

The authors declare no conflict of interest.

\section{APPENDIX}

The Fukushima Health Management Survey Group Chairpersons: Masafumi Abe (Director General, Radiation Medical Center for the Fukushima Health Management Survey), Shunichi Yamashita (Vice Director, Radiation Medical Center for the Fukushima Health Management Survey), Kenji Kamiya (Vice Director, Radiation Medical Center for the Fukushima Health Management Survey), Seiji Yasumura (Vice Director, Radiation Medical Center for the Fukushima Health Management Survey), Makoto Akashi (National Institute of Radiological Sciences), Kazunori Kodama, and Kotaro Ozasa (The Radiation Effects Research Foundation), Hirooki Yabe (Chairman of Mental Health Survey, Radiation Medical Science Center for the Fukushima Health Management Survey).

Participating Other Expert Committee Members, Advisors, and Staffs in Mental Health and Lifestyle Survey of the Fukushima Health Management Survey: Ohtsura Niwa, Akira Ohtsuru, Shiro Matsui, Shinichi Niwa, Tetsuya Ohira, Yasuto Kunii, Shuntaro Itagaki,
Tetsuya Shiga, Hajime Iwasa, Yoko Nakayama, Misao Ohta, Aya Goto, Mitsuru Hisata, Norito Kawakami, Mitsuaki Hosoya, Mayumi Harigane, Akiko Yagi, Yuichi Oikawa, Yuki Ueda, Noko Horikoshi, Yu-ya Kashiwazaki, Tsuyoshi Takeda, Tetsunobu Hata, Hiroyuki Sugimoto, Yukiko Itoh, Yuko Hino, Keisuke Hiyamizu, Kuni Sugano, Suzuko Yasuhara, Shidu Igarashi, Ai Kawamura. Aiko Matsuda, Mariko Hara, Yuriko Kimura, Yuki Kumasaka, Natsumi Sasaki, Miho Otoji, Ryoichi Kurosawa, Fumiko Mori.

\section{REFERENCES}

1. Nagataki S, Takamura N, Kamiya K, Akashi M. Measurements of individual radiation doses in residents living around the Fukushima Nuclear Power Plant. Radiat Res, 180 : 439-447, 2013.

2. Bromet EJ. Emotional consequences of nuclear power plant disasters. Health Phys, 106 : 206210, 2014.

3. Bromet EJ, Havenaar JM. Psychological and perceived health effects of the Chernobyl disaster : a 20-year review. Health Phys, 93 : 516-521, 2007.

4. WHO (World Health Organization) 2005a. Health Effects of the Chernobyl Accident and Special Health Care Programmes. Available : http:// www.who.int/ionizing_radiation/a_e/chernobyl/EGH\%20Master\%20file\%202005.08.24.pdf [accessed 20 December, 2013].

5. WHO (World Health Organization) 2005b. Chernobyl : The True Scale of the Accident ; 20 Years Later a UN Report Provides Definitive Answers and Ways to Repair Lives [Press Release]. Available : http://www.who.int/mediacentre/news/ releases/2005/pr38/en/print.html [accessed 20 December, 2013].

6. Radiation Medical Science Center for the Fukushima Health Management Survey, Fukushima Medical University.

http://www.fmu.ac.jp/radiationhealth/ [accessed 20 December, 2013].

7. Proceedings of the 11th Fukushima Prefectural Oversight Committee Meeting, Mental health and Lifestyle Survey, 5 Jun 2013, Japanese version. http://www.pref.fukushima.jp/imu/kenkoukanri/ 250605siryou4.pdf_[accessed 20 December, 2013]

8. Proceedings of the 12th Fukushima Prefectural Oversight Committee Meeting, Mental Health and Lifestyle Survey, 20 Aug 2013, Japanese version, http://www.pref.fukushima.jp/imu/kenkoukanri/ 250820siryou4.pdf_[accessed 20 December, 2013]

9. Yasumura S, Hosoya M, Yamashita S, Kamiya K, Abe M, Akashi M, et al. Study Protocol for the Fukushima Health Management Survey. J Epide- 
miol, 22 : 375-383, 2012.

10. Kessler RC, Barker PR, Colpe LJ, Epstein JF, Gfroerer JC, Hiripi E, et al. Screening for serious mental illness in the general population. Arch Gen Psychiatry, 60 : 184-189, 2003.

11. Blanchard EB, Jones-Alexander J, Buckley TC, Forneris CA. Psychometric properties of the PTSD Checklist (PCL). Behav Res Ther, 34 : 669-673, 1996.

12. Furukawa TA, Kessler RC, Slade T, Andrews G. The performance of the K6 and K10 screening scales for psychological distress in the Australian National Survey of Mental Health and Well-Being. Psychol Med, 33 : 357-362, 2003.

13. Sakurai K, Nishi A, Kondo K, Yanagida K, Kawakami N. Screening performance of K6/K10 and other screening instruments for mood and anxiety disorders in Japan. Psychiatry Clin Neurosci, 65 : 434-441, 2011.

14. Ewing JA. Detecting alcoholism. The CAGE questionnaire. JAMA, 252 : 1905-1907, 1984.

15. Sheehan DV. The Anxiety Disease. Charles Scribner and Sons, New York, 1983.

16. Yoshida T, Ohtsubo T, Tsuchida H. Study of reliability and validity of a Japanese version of Sheehan Disability Scale (SDISS) (in Japanese). Japanese Journal of Clinical Psychopharmacology, 7 : 1645-1653, 2004.

17. Lubben, JE. Assessing social networks among elderly populations. Family \& Community Health, 11 : 42-52, 1988.

18. Kurimoto A, Awata S, Ohkubo T, Tsubota-Utsugi M, Asayama K, Takahashi K, et al. Study of reliability and validity of a Japanese brief version of Lubben Social Network Scale (LSNS-6) (in Japanese). Nihon Ronen Igakkai Zasshi, 48 : 149-157, 2011.

19. Lindell MK, Barnes VE. Protective response to technological emergency : risk perception and be- havioral intention. In : Silver EG, editor. Nuclear Safety ; College Station, TX, USA : Hazard Reduction and Recovery Center ; 1986. p. 457467.

20. Goodman R. Psychometric properties of the strengths and difficulties questionnaire. J Am Acad Child Adolesc Psychiatry, 40 : 1337-1345, 2001.

21. Matsuishi T, Nagano M, Araki Y, Tanaka Y, Iwasaki M, Yamashita Y, et al. Scale properties of the Japanese version of the Strengths and Difficulties Questionnaire (SDQ) : A study of infant and school children in community samples. Brain Dev, 30 : 410-415, 2008.

22. Kawakami, N. National survey of mental health measured by $\mathrm{K} 6$ and factors affecting mental health status (in Japanese) in Research on Applied Use of Statistics and Information, Health Labour Sciences Research Grant 2006/2007.

23. Stellman JM, Smith RP, Katz CL, Sharma V, Charney DS, Herbert R, et al. Enduring mental health morbidity and social function impairment in World Trade Center rescue, recovery, and cleanup workers : the psychological dimension of an environmental health disaster. Environ Health Perspect, 116 : 1248-1253, 2008.

24. DiGrande L1, Perrin MA, Thorpe LE, Thalji L, Murphy J, Wu D, Farfel M, Brackbill RM. Posttraumatic stress symptoms, PTSD, and risk factors among lower Manhattan residents 2-3 years after the September 11, 2001 terrorist attacks. J Trauma Stress, 21 : 264-273, 2008.

25. North CS, Ringwalt CL, Downs D, Derzon J, Galvin D. Postdisaster course of alcohol use disorders in systematically studied survivors of 10 disasters. Arch Gen Psychiatry, 68 : 173-180, 2011. 